\title{
Changes in the chemical profile of cephalic salivary glands of Scaptotrigona postica (Hymenoptera, Meliponini) workers are phase related
}

\author{
Silvana B. Poiani ${ }^{1, *}$, E. David Morgan ${ }^{2}$, Falko P. Drijfhout ${ }^{2}$ and Carminda da Cruz-Landim ${ }^{1}$
}

\begin{abstract}
Most advanced eusocial bees recruit their nest mates to food resources. Recent studies in Meliponini species have revealed that the cephalic salivary (labial) glands (CSGs) are responsible for the production of scent trail pheromones. Studies on CSGs have shown that changes occur in worker glandular cell morphology from emergence from brood combs until forager phase, which may be correlated to changes in the composition of the CSG secretion. However, the composition of the CSG secretion and the chemical changes that occur in it according to the worker's life phase or tasks performed are unknown for many species, including Scaptotrigona postica. In this study, the chemical profile of CSG secretion in $S$. postica workers was studied. Glands were taken from specimens that were newly emerged (NE), working in the brood comb area (CA) and foraging (FO), and were analyzed by gas chromatography-mass spectrometry. The results showed that the glandular secretion consists of oxygenated compounds of middle volatility (acids, alcohols, aldehydes, ketones, esters and ether), and their quantity varies among the different life phases, increasing as the individual moves from intra- to extra-colonial activities. The NE phase contained the smallest variety and quantity of compounds. Because of the variability of compounds, the CA workers were separated into three subgroups according to the chemical constitution of their secretion. Forager workers showed the largest quantity and variety of chemical compounds. The major compounds in forager gland secretion were $7-$ hexadecen-1-yl acetate and 5-tetradecen-1-yl acetate. Statistical analysis indicates that the chemical composition of glandular secretion is phase related.
\end{abstract}

KEY WORDS: GC-MS, Ester, Labial glands, Life phases, Multivariate statistics, Stingless bee

\section{INTRODUCTION}

Stingless bees are a large group of eusocial bees with approximately 500 species, comprising the tribe Meliponini (Michener, 2007). As for all eusocial bees, members of a colony are divided into castes. The caste of workers is responsible for brood care, building, attending the queen, guarding the entrance and activities outside the nest.

The salivary system of bees comprises the salivary (also known as the labial), mandibular and hypopharingeal glands, named after the mouth appendices to which they are connected. In all species of

\footnotetext{
${ }^{1}$ Departamento de Biologia, Universidade Estadual Paulista - UNESP, Instituto de Biociências, Rio Claro, SP 13506-900, Brazil. ${ }^{2}$ Chemical Ecology Group, LennardJones Laboratories, Keele University, Staffordshire ST5 5BG, UK.

*Author for correspondence (silbeani@gmail.com)
}

Received 23 April 2015; Accepted 23 June 2015 adult bees, salivary glands are paired structures located in the thorax, but some species from the Apinae subfamily have developed a branch of salivary glands in the head called cephalic salivary glands (CSGs) (Cruz-Landim, 1967).

All salivary glands, including the CSGs, have several functions in eusocial bees that go beyond food ingestion (Poiani and da CruzLandim, 2010a). Heselhaus (1922) was one of the first researchers to suggest the function of the CSG secretion of Apis mellifera; specifically, softening wax during nest building. Later, Simpson (1960) described lubrication of the mouthparts as the function of the CSGs. In stingless bees, Santos et al. (2009) suggested that the CSG secretions of Plebeia emerina nurses aid in the handling in the colony of resins collected in the field, and other recent studies have shown that Trigona recursa (Jarau et al., 2004, 2006), Trigona spinipes (Schorkopf et al., 2007), Geotrigona mombuca (Stangler et al., 2009) and Trigona corvine (Jarau et al., 2010a) use the secretion of the CSGs as a scent trail to indicate a food source to nest mates, by producing ester compounds. In another stingless bee species, Melipona beecheii, the CSGs produce geraniol, which has been found to affect caste determination by significantly increasing the number of larvae that develop into queens (Jarau et al., 2010b).

The functions of the CSGs are known to vary among species, sex, caste, physiological state and roles of individuals in the colony. In many Bombus species, variation between sexes and castes occurs not only in the development of the CSGs but also in the identity and function of the secreted compounds. In general, the CSGs of sterile females of Bombus terrestris produce larger amounts of wax esters (mainly dodecyl esters) than the CSGs of fertile females of this species (Amsalem et al., 2014). Males of Bombus species use secretions of the CSGs for territorial marking and female attraction (Amsalem et al., 2014; Bergman and Bergström, 1997; Bertsch et al., 2005; Kullenberg et al., 1973; Terzo et al., 2007). In A. mellifera, the hydrocarbons in the glandular secretions are also present in the cuticle of forager workers (Arnold and DelageDarchen, 1978; Arnold et al., 1996; Poiani, 2012), suggesting that the CSGs might be the source of cuticular hydrocarbons in this species. Histochemical and ultrastructural studies of CSGs indicate that a lipid-like secretion is produced in stingless bees (Poiani and Cruz-Landim, 2009, 2010c), and Elias-Santos et al. (2013) in a proteome analysis of CSG of Melipona quadrifasciata anthidioides found enzymes relevant to lipid metabolism.

In Scaptotrigona postica and A. mellifera workers, the CSGs were shown to begin to produce secretion soon after worker emergence and accumulate the secretion continually in the alveolar lumen throughout their life, and thus subsequent changes in both the intensity of secretory activity and the chemical composition of the secretion would be expected (Poiani and Cruz-Landim, 2009, 2010a,b,c). Francke et al. (1983) studied the CSGs of S. postica workers, but they used whole-head extracts, including other glands 
and cuticle compounds, so the identified compounds are not exclusive to the CSGs. Therefore, little is known about the chemical properties of the CSGs of S. postica. Addressing this gap in evidence might allow understanding of the dynamics of secretion synthesis of these glands and how it may affect social behaviour as the tasks performed are related to the bees' physiological state.

The tasks of workers in eusocial bee colonies are performed according to a division of labour based on age polyethism. The ability to perform a given task is achieved through physiological maturity, acquired in steps with the advancement of age (Ribbands, 1953; Oster and Wilson, 1978). The pertinent literature reporting several aspects of labour division in S. postica (Akahira et al., 1970; Dias and Simões, 1972; Bego, 1982) shows that the sequence of worker activities is similar to that of other eusocial bees: newly emerged (NE) workers clean themselves of brood debris and spend much of the time inactive or grooming. In the subsequent age step, in which they work in the nest brood area (CA, generally named the nurse phase), they display a variety of actions directed mainly, but not solely, at aiding the queen in laying her eggs and brood care. The phase of work inside the nest ends when workers became foragers (FO), at which point they go out to obtain resources for the colony. Between the duties inside the nest and those outside, the worker passes through a phase in which it remains at the nest entrance functioning as guard. The labour division is plastic. The age at which the duties are performed and time expended in each task vary with the species and colony state.

In view of the above, the present study aimed to identify and quantify the volatile compounds that are present in the CSG secretions of $S$. postica during different life phases using gas chromatographymass spectrometry (GC-MS), and subsequently identify possible correlations between the changes in secretion composition and the status of the worker in the colony by statistical analysis.

\section{RESULTS}

The CSG secretion of $S$. postica workers varied qualitatively and quantitatively not only across the analysed phases (NE, CA and FO) but also within them. In general, the identified compounds included: acids, alcohols, aldehydes, ketones, esters and ether (Table 1).

The CSG of the NE phase produce little secretion. Among the nine identified compounds in this life phase, 2-tridecanone, ethyl oleate and nonanal were the most abundant.

The CA phase showed large qualitative and quantitative variations in glandular secretion composition. As a result, the phase was separated into three groups, CA1, CA2 and CA3,

Table 1. Quantities of chemical compounds found in the cephalic salivary gland (CSG) secretions of Scaptotrigona postica workers

\begin{tabular}{|c|c|c|c|c|c|c|c|}
\hline ID & $\mathrm{KI}$ & Compound & $\mathrm{NE}(N=8)$ & CA1 $(N=3)$ & CA2 $(N=5)$ & CA3 $(N=14)$ & $\mathrm{FO}(N=8)$ \\
\hline \multicolumn{8}{|l|}{ Acid } \\
\hline $\mathrm{A} 1$ & 894 & Nonanoic acid & - & - & $0.70 \pm 0.95$ & - & $0.20 \pm 0.53$ \\
\hline $\mathrm{A} 2$ & 1069 & Decanoic acid & - & - & $5.30 \pm 3.58$ & - & $1.00 \pm 2.82$ \\
\hline A3 & 1383 & Dodecanoic acid & - & - & $0.46 \pm 1.01$ & - & - \\
\hline A4 & 1686 & Tetradecanoic acid & - & - & $8.42 \pm 5.22$ & - & $0.32 \pm 0.85$ \\
\hline A5 & 1820 & Pentadecanoic acid & - & - & - & $1.80 \pm 1.76$ & $0.15 \pm 0.41$ \\
\hline A6 & 1970 & Hexadecanoic acid & $5.79 \pm 1.36$ & - & $30.88 \pm 12.09$ & - & $0.48 \pm 1.34$ \\
\hline \multicolumn{8}{|l|}{ Alcohol } \\
\hline $\mathrm{Al} 7$ & 1307 & 2-Tridecanol & - & $7.96 \pm 4.35$ & $0.45 \pm 0.98$ & - & - \\
\hline Al8 & 1540 & 5-Tetradecen-1-ol & - & - & - & $0.33 \pm 1.56$ & $4.69 \pm 5.25$ \\
\hline Al9 & 1836 & 7-Hexadecen-1-ol & - & - & - & $1.29 \pm 3.52$ & $11.2 \pm 8.93$ \\
\hline Al10 & 1900 & 2-Heptadecanol & - & - & - & $2.91 \pm 5.03$ & $0.40 \pm 0.57$ \\
\hline \multicolumn{8}{|c|}{ Aldehyde } \\
\hline Ad11 & 348 & Octanal & - & - & $1.75 \pm 0.07$ & - & $0.33 \pm 0.88$ \\
\hline Ad12 & 614 & Nonanal & $6.15 \pm 12.03$ & - & $7.39 \pm 3.42$ & - & $0.99 \pm 2.65$ \\
\hline Ad13 & 808 & Decanal & $3.31 \pm 9.34$ & - & $16.46 \pm 9.80$ & - & $3.12 \pm 8.77$ \\
\hline Ad14 & 967 & 2-Decenal & - & - & - & - & * \\
\hline Ad15 & 993 & Undecanal & - & - & $0.79 \pm 0.80$ & - & $0.25 \pm 0.67$ \\
\hline Ad16 & 1151 & 2-Undecenal & - & - & $0.20 \pm 0.43$ & * & * \\
\hline Ad17 & 1516 & Tetradecanal & - & - & - & - & * \\
\hline Ad18 & 1772 & 7-Hexadecenal & - & $2.96 \pm 1.12$ & - & $0.48 \pm 0.72$ & $0.09 \pm 0.14$ \\
\hline \multicolumn{8}{|l|}{ Ketone } \\
\hline K19 & 951 & 2-Undecanone & - & - & - & * & - \\
\hline K20 & 1327 & 2-Tridecanone & $64.41 \pm 27.25$ & $53.18 \pm 18.83$ & $9.02 \pm 8.84$ & $3.08 \pm 2.49$ & $0.46 \pm 0.79$ \\
\hline $\mathrm{K} 21$ & 1638 & 2-Pentadecanone & $1.35 \pm 3.79$ & $8.51 \pm 4.23$ & $2.27 \pm 2.55$ & $1.10 \pm 1.00$ & $0.18 \pm 0.14$ \\
\hline K22 & 1926 & 2-Heptadecanone & $0.22 \pm 0.61$ & $1.52 \pm 0.88$ & $4.60 \pm 4.46$ & $7.31 \pm 3.05$ & $4.45 \pm 2.33$ \\
\hline \multicolumn{8}{|l|}{ Ester } \\
\hline E23 & 1427 & Ethyl dodecanoate & - & - & - & $0.11 \pm 0.18$ & * \\
\hline E24 & 1716 & Dodecyl butyrate & - & - & - & $2.03 \pm 2.49$ & $1.69 \pm 1.85$ \\
\hline E25 & 1730 & Tridecyl butyrate & - & $3.05 \pm 1.51$ & - & - & - \\
\hline E26 & 1968 & 5-Tetradecen-1-yl acetate & - & - & $2.32 \pm 2.16$ & $19.01 \pm 4.53$ & $17.71 \pm 6.22$ \\
\hline E27 & 1994 & Tetradecyl butyrate & - & - & - & $7.15 \pm 2.64$ & $5.53 \pm 2.50$ \\
\hline E28 & 2127 & Methyl oleate & $1.09 \pm 3.07$ & $3.26 \pm 2.17$ & - & - & $0.11 \pm 0.11$ \\
\hline E29 & 2205 & Ethyl oleate & $13.25 \pm 9.57$ & $16.59 \pm 6.60$ & - & - & - \\
\hline E30 & 2219 & 7-Hexadecen-1-yl acetate & $4.45 \pm 2.50$ & - & $7.42 \pm 6.40$ & $52.52 \pm 9.71$ & $43.45 \pm 12.47$ \\
\hline \multicolumn{8}{|l|}{ Ether } \\
\hline T31 & 2245 & 1-Methoxy eicosane & - & - & - & - & $1.01 \pm 0.89$ \\
\hline
\end{tabular}


according to the chromatographic results. The glandular secretion of CA1 contained eight different compounds, with 2-tridecanone, ethyl oleate and 2-pentadecanone as the major compounds. A greater variety (quality) and quantity of compounds were found in the two remaining groups, CA2 and CA3. The glandular secretion of the CA2 group contained 16 compounds, and hexadecanoic acid, decanal and 2-tridecanone were the most prevalent. The CA3 group contained 15 compounds, and of these 7-hexadecen-1-yl acetate, 5-tetradecen-1-yl acetate and 2-heptadecanone were at a higher level.

The FO phase presented the same acetates, 7-hexadecen-1-yl and 5-tetradecen-1-yl, as chief glandular compounds followed by tetradecanyl butyrate. In this worker life phase, 26 compounds were found (Table 1).

The three ketones, 2-tridecanone, 2-pentadecanone and 2heptadecanone, were common during all worker life phases. However, their concentration in CSG secretion increased or decreased as the individual changed from intra-nest to field tasks: the concentrations of 2-tridecanone and 2-pentadecanone decreased, while 2-heptadecanone increased when the worker became a forager.

A hierarchical cluster analysis (HCA) dendrogram separated the workers into three major groups (Fig. 1): (1) NE+CA1, containing almost all the NE individuals (except NE5) and all CA1 individuals; (2) CA2+NE5, containing all CA2 individuals and the individual discordant $\mathrm{NE}$ (NE5); and (3) $\mathrm{CA} 3+\mathrm{FO}$, containing all CA3 and FO individuals.

The principal component analysis (PCA) also divided the workers into three major groups (Fig. 2A) and correlated them with the chemical compounds found in their secretion (Fig. 2B). The three principal components generated by PCA (F1, F2 and F3) explain $51.20 \%$ of the variability within the samples. The plot of F1 versus F2 of the PCA and which compounds are correlated to groups of workers are shown in Fig. 2.

The HCA and PCA do not describe how the chemical compounds are used to determine the groups. As a result, discriminant analysis (DA) was performed to verify whether individuals sufficiently represent the phase to which they were allocated at the time of specimen capture and to identify which chemical compounds are important in discriminating among the groups. The three ketones 2-tridecanone, 2-pentadecanone and 2-heptadecanone were used in the DA because they were the only compounds present in all of the groups studied here. The DA showed that 2-tridecanone is primarily responsible for discrimination among the phases. The Fisher's distance showed that NE and CA1 differ from each other and from CA2, CA3 and FO. However, the DA did not discriminate among these last three groups (Table 2).

The DA statistics were used to obtain the Mahalanobis distance among the phases (Table 3), which measures the average, or centroid, of the major compound separating the groups, which was 2-tridecanone (but note that this is not the only important compound). The centroids also indicate the distances among the phases. According to Table 3, the NE and CA1 groups are closest to each other, as observed in the HCA dendrogram (Fig. 1), and CA2, CA3 and FO show closest proximity to each other (Fig. 3).

\section{DISCUSSION}

This is the first study to describe the chemical profile of worker bee CSG throughout adult life, showing the dynamics of compound presence and absence on secretion. Furthermore, the study indicates the main compounds responsible for differentiating workers' life phases and associated tasks.

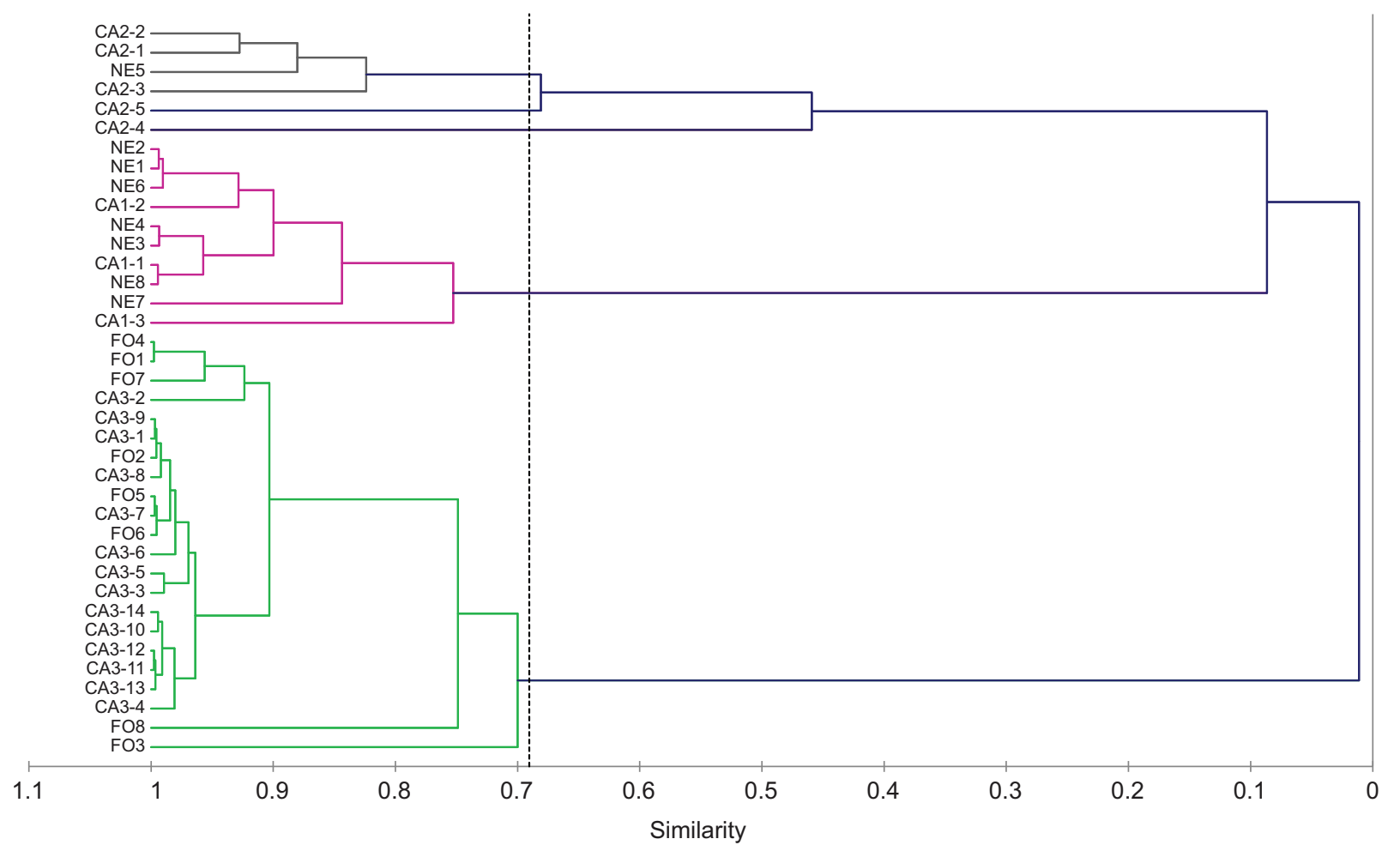

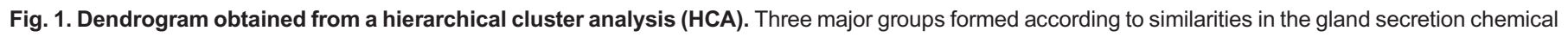
profiles. Note that the workers captured at the brood comb area (CA) were divided into three subgroups, CA1, CA2 and CA3, as shown in Table 1. The subgroup CA1 is similar to NE (newly emerged); CA2 and an individual from NE (NE5) represent an intermediate major group between CA1+NE and the third group, which consists of CA3 and FO (foragers). 

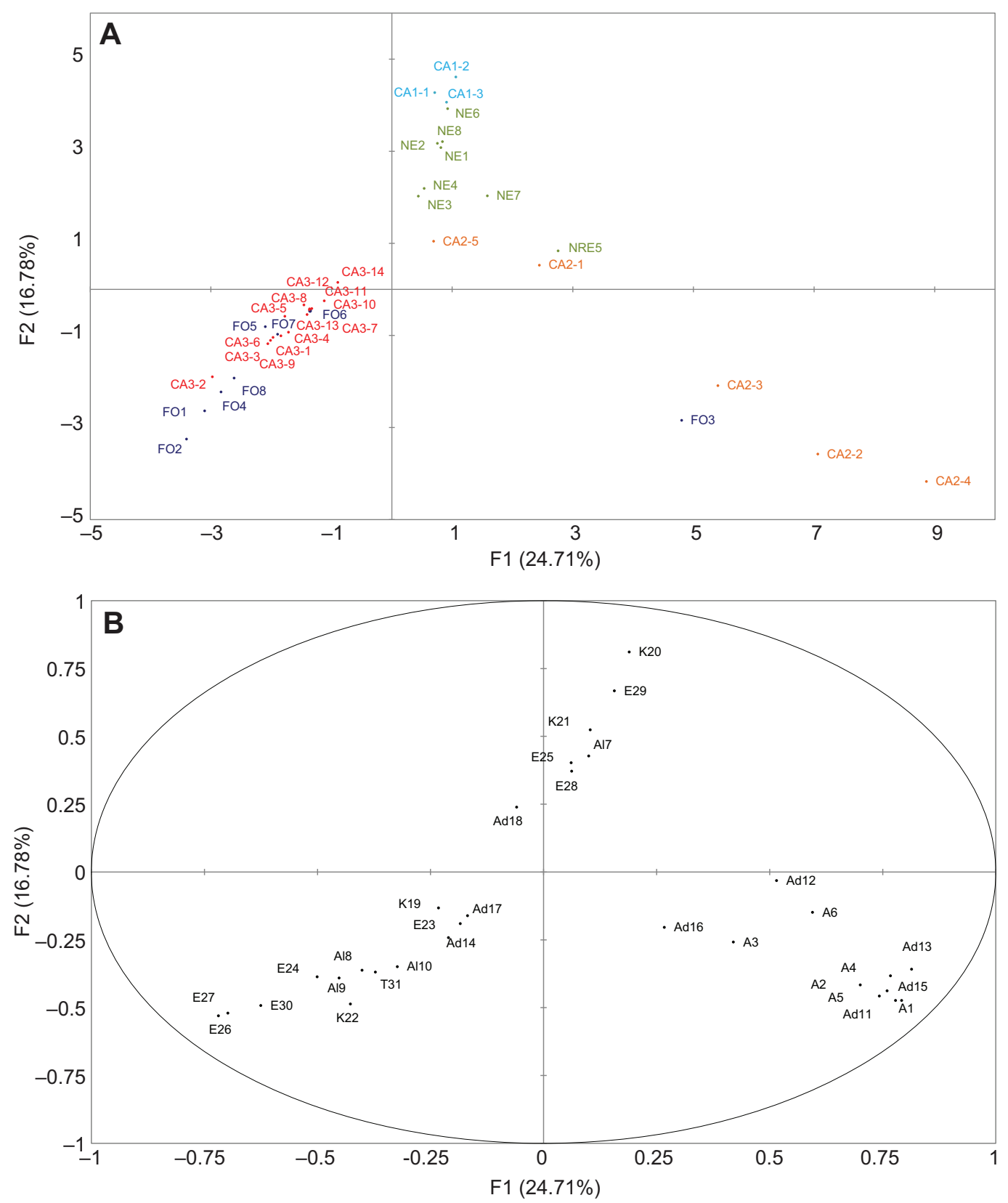

Fig. 2. Graphs of the principal component analysis (PCA). The main components $F 1$ and $F 2$ explain $41.48 \%$ of the variability of the samples. (A) Three groups were formed: (1) NE, CA1 and two individuals from CA2; (2) CA3 and FO; and (3) CA2 and FO3. (B) The chemical compounds as represented by their identifiers (IDs) (Table 1) are distributed into quadrants that correspond to the groups presented in $\mathrm{A}$.

According to morphological data of the CSGs of $S$. postica workers (Poiani and Cruz-Landim, 2009, 2010a,b,c), the glands start to produce secretion when workers emerge from brood combs

Table 2. $P$-values from Fisher discriminant analysis of the compound profiles of CSGs across $S$. postica life phases

\begin{tabular}{llllll}
\hline & NE & CA1 & CA2 & CA3 & FO \\
\hline NE & 1 & $<0.0001$ & $<0.0001$ & $<0.0001$ & $<0.0001$ \\
CA1 & $<0.0001$ & 1 & $<0.0001$ & $<0.0001$ & $<0.0001$ \\
CA2 & $<0.0001$ & $<0.0001$ & 1 & 0.134 & 0.465 \\
CA3 & $<0.0001$ & $<0.0001$ & 0.134 & 1 & 0.162 \\
FO & $<0.0001$ & $<0.0001$ & 0.465 & 0.162 & 1 \\
\hline
\end{tabular}

Bold indicates statistical significance. (newly emerged workers), apparently without being delivered until the secretion accumulates in the alveoli for use when the worker is performing field activities. In the present work, the statistical

Table 3. Mahalanobis distance analysis of CSG compound profiles across S. postica life phases

\begin{tabular}{|c|c|c|c|c|c|}
\hline & $\mathrm{NE}$ & CA1 & CA2 & CA3 & FO \\
\hline $\mathrm{NE}$ & 0 & 15.831 & 24.798 & 32.570 & 27.895 \\
\hline CA1 & 15.831 & 0 & 17.174 & 28.261 & 24.799 \\
\hline CA2 & 24.798 & 17.174 & 0 & 1.738 & 0.908 \\
\hline CA3 & 32.570 & 28.261 & 1.738 & 0 & 1.149 \\
\hline $\mathrm{FO}$ & 27.895 & 24.799 & 0.908 & 1.149 & 0 \\
\hline
\end{tabular}




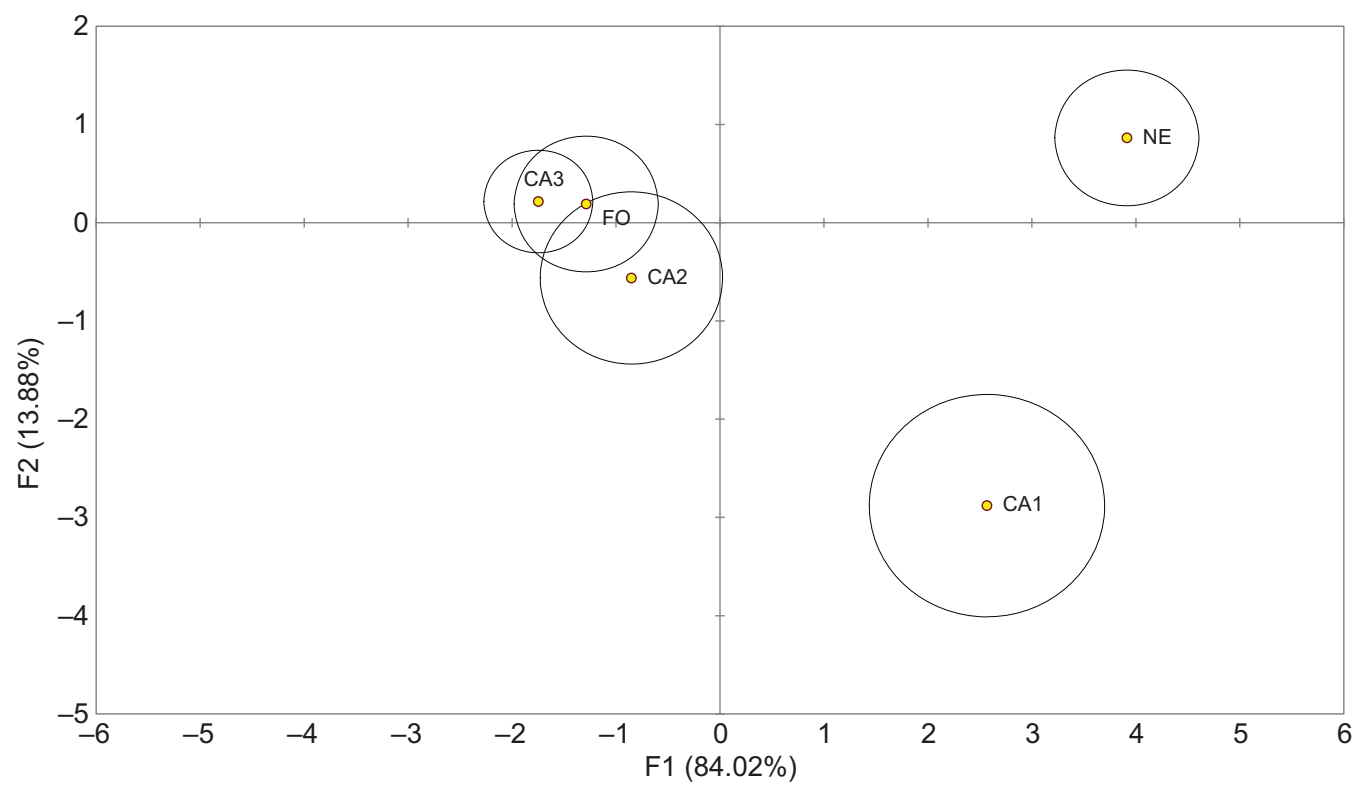

Fig. 3. Discriminant analysis (DA) showing the centroids obtained for NE, CA1, CA2, CA3 and FO. Components F1 and F2 explain $97.9 \%$ of the discrimination between groups. NE and CA1 are completely separated from each other and from the other groups (CA2, CA3 and FO). CA2, CA3 and FO have overlaps, indicating a greater proximity among them and, consequently, chemical similarities in the glandular secretion. The chemical compound responsible for discrimination among groups is 2-tridecanone.

analysis (HCA and PCA) showed that the composition of the secretion changes gradually from NE to FO. This gradual change is seen in the variability of the CA phase, which determines its division into three subgroups. Concerning the CA subgroups, CA1 has a similar chemical profile to that of NE, and CA3 to that of FO. Therefore, the CSG secretion from bees working in the brood comb gradually acquires forager characteristics. In terms of the glandular function, this phase seems to be a transitional one during which the secretion is produced, modified and stored ready to be delivered in the FO phase. The cause of the variability in the secretion composition during CA may be related to the actual task that the bee is displaying, but making this correlation is impossible as the bee's duty or age at capture was not registered. Although not very probable, the variability of secretion composition could also be due to genetic differences among the workers. While all of them are daughters of the same queen, $S$. postica can mate once or with up to six different males (Paxton, 2000). Therefore, the possibility of having a polyandrous queen could also explain the diversity inside the CA group in the present work. However, under the present conditions, in which the CA bees comprise individuals captured working in the brood area without age or specific duty correlation, the changes in secretion composition were taken as corresponding to a continuous 'maturation' toward the FO composition. According to Johnson (2010) 'members of the nursing caste are proposed to be pushed from their caste by the development of workers behind them in the temporal caste sequence, while middle-aged bees are pulled from their caste via interactions with the caste ahead of them', suggesting that CA1 is chemically closer to NE and CA3 is chemically closer to FO as indicated by the statistics.

DA was done by selecting only compounds present in all of the worker groups (2-tridecanone, 2-pentadecanone and 2heptadecanone) as the analysis did not allow zero values to be used. The results showed that 2-tridecanone was responsible for separating the workers into phase-related groups, but all exclusive compounds found in each group analysed also act as phase-related indicators.
Previous studies on the CSGs of stingless bees examined only the glandular compounds of forager workers and stated that the secretion is a scent trail pheromone containing mainly esters. The hexyl decanoate contained in the CSG of the T. recursa forager was the first scent trail pheromone described for meliponines (Jarau et al., 2006). After this first study, Schorkopf et al. (2007) found octyl octanoate in the glandular secretion of $T$. spinipes foragers, Stangler et al. (2009) found farnesyl butanoate in the CSG secretion of Geotrigona mombuca foragers and Jarau et al. (2010a) reported that the CSG secretion of $T$. corvine foragers is composed of various esters that mark a scent trail. In this study, the primary compounds in the CSG secretion of S. postica FO were 7-hexadecen-1-yl acetate and 5-tetradecen-1-yl acetate. These chemicals have moderate volatility, making them candidates for pheromones. Therefore, the FO may use the CSG secretion as scent trail markers to indicate food sources to nest mates, as already demonstrated for other species of stingless bees that have esters as the primary CSG compound in foragers (Jarau et al., 2006, 2010a; Schorkopf et al., 2007; Stangler et al., 2009). Furthermore, odorant-binding protein made up a significant fraction of the proteins identified by Elias-Santos et al. (2013), suggesting an important role of the CSG in chemical communication among bees.

Different species of bumblebees, especially males, have been widely used for studying the chemical composition and function of CSG secretion (Bergman and Bergström, 1997; Coppée et al., 2008; Šobotník et al., 2008; Terzo et al., 2007). As in S. postica forager workers, 7-hexadecen-1-yl acetate is the primary compound found in the CSG of male Bombus sylvarum (Bergström et al., 1985) and probably functions as a pheromone that marks scent flight routes. The same pheromone function is performed by 2,3-dihydrofarnesol, which is also found in the CSG of B. terrestris (Šobotník et al., 2008).

NE phase specimens were collected immediately after emergence from the brood comb to prevent them from performing any specific task in the colony. During this phase, the workers start to produce and accumulate secretion in CSGs, mainly ketones. Specimens in 
the CA phase are bees captured indiscriminately while working at brood combs where they perform a variety of tasks such as manipulation of wax for nest building, supplying brood cells with food, aiding the queen in egg laying, closing cells where the queen has laid eggs or laying trophic or functional eggs themselves. The heterogeneity in secretion composition during the CA phase might be explained by the heterogeneity of this group of workers, a group that displays several tasks in the process of transition from NE to FO, i.e. the transition from inner- to outer-colony tasks. However, reports in the literature do not describe which intra-colonial function the secretion might have, and morphological studies (Poiani and Cruz-Landim, 2009, 2010a) do not indicate secretion used by bees working inside the nest. Indeed, little is known about the composition of CSG secretion and how it affects stingless bees still inside the colony. Santos et al. (2009) suggested that the CSG secretions of Plebeia emerina nurses aid in the handling of the colony resins collected in the field but this hypothesis is only supported by behavioural observations because no chemical analysis of secretion was performed.

In conclusion, the CSG secretion in bees shows great plasticity and changes as the individual acquires new competence in the tasks performed. The main compounds in FO glandular secretion should be tested in order to clarify whether those compounds are scent trail pheromones.

\section{MATERIALS AND METHODS \\ Study species}

Scaptotrigona postica (Latreille 1807) is a eusocial species of stingless bee native to Brazil; individuals are medium sized $(1.2 \mathrm{~cm})$ and live in colonies of around 10,000 bees with a single physogastric queen. The species is found in south, southeast, centre-west and north Brazil. All bees used in this study were taken from a single 10-year-old colony, in Meliponary at the Universidade Estadual Paulista-UNESP, Institute of Biosciences, Rio Claro, Brazil.

Chemical analysis of glandular secretion using GC-MS was performed. To do so, CSG were dissected from workers at the following life phases: $\mathrm{NE}$, newly emerged workers, collected at the time of emergence from their brood cells; CA, workers performing tasks at the brood comb area, provisioning or constructing cells; and FO, forager workers at the nest entrance, returning from foraging activities to the nest with pollen on their legs. Initially, eight NE, eight $\mathrm{CA}$ and eight FO glands were used. An additional 14 glands from the CA phase were used because of their highly variable chemical composition, resulting in a total of 22 samples for the CA phase.

\section{Methods}

\section{The chemical profile of glandular secretions}

Chemical analyses were conducted in the Lennard-Jones Laboratories of the Chemical Ecology Group at Keele University, Staffordshire, UK. The samples were analysed using gas chromatography (Hewlett Packard 6890) equipped with an HP-5MS column (30 m length, $0.25 \mathrm{~mm}$ diameter) coupled directly to a 5973 mass detector (mass spectrometer using ionization impaction electron $-70 \mathrm{eV}$ ). The solid-phase extraction developed by Morgan (1990) was used. The glands were dissected and isolated in buffered saline solution for insects under stereomicroscope and inserted into a thin glass capillary tube, approximately $5 \mathrm{~cm}$ in length with a blind bottom. The open end of the capillary tube was sealed using a flame, and the capillaries were inserted individually into the chromatograph and were broken to release the compounds.

The samples were processed using the splitless mode. The temperature protocol used was: $40^{\circ} \mathrm{C}$ for $1 \mathrm{~min}$, increased to $320^{\circ} \mathrm{C}$ at a rate of $15^{\circ} \mathrm{C} \mathrm{min}^{-1}$ and maintained for $10 \mathrm{~min}$. Helium was used as the carrier gas at a constant rate of $1.0 \mathrm{ml} \mathrm{min}{ }^{-1}$. The $n$-alkanes $\mathrm{C}_{21}-\mathrm{C}_{33}$ were injected using the same temperature protocol and their retention times $\left(t_{\mathrm{r}, \mathrm{C} 21}=13.54\right.$ and $t_{\mathrm{r}, \mathrm{C} 33}=19.55$ ) were used to calculate the Kovats indices (Kovats, 1958).
Quantification was based on the peak areas in the resulting chromatograms (Singer and Espelie, 1992) and the average percentage of each compound was calculated for statistical analysis. The data were analysed using the GCMS Solutions program for Windows (Shimadzu Corporation). Compounds were identified by comparing the retention indices of the peaks on the HP-5MS column with literature values. The final confirmation of compounds was made by computer matching of the mass spectra of peaks with Wiley and NIST libraries.

\section{Statistical analyses}

For the purpose of the statistical analyses, all compounds were assigned an identifier (ID). Multivariate statistical tests were used to analyse the material. HCA was used to determine how individuals were distributed in preestablished phases (NE, CA and FO) according to the similarities using all of the chemical compounds found in the glandular secretions. PCA was used to assess correlations between the compounds and the phases of the workers. Discriminant analysis (DA) was used to verify whether the phases were correctly classified within the pre-established groups (NE, CA and FO) and to identify which chemical compounds were responsible for the discrimination among the groups. To perform the DA, only the compounds common to all phases were selected. Statistical significance for DA was established at $P<0.0001$. The results of Fisher discriminant analysis and the Mahalanobis distance analysis are reported. The latter was based on the centroid that was obtained by averaging the compound 2-tridecanone in each group because this compound showed the highest discriminating power. All statistical tests were performed using average percentage original data and the software XLSTAT 2011.

\section{Acknowledgements}

The authors would like to thank the Fundação de Amparo à Pesquisa do Estado de São Paulo (FAPESP) for their support via a fellowship and Magdalena Rzewuska for language revision.

\section{Competing interests}

The authors declare no competing or financial interests.

\section{Author contributions}

All authors designed the experiments; S.B.P. collected bees, dissected the glands and performed the chemical experiments; S.B.P., E.D.M. and F.P.D. analysed the chemical data; S.B.P. carried out statistical analyses; S.B.P. and C.d.C.-L. analysed the statistical results; S.B.P. and C.d.C.-L. wrote the paper; all authors contributed to the final version of the manuscript.

\section{Funding}

S.B.P. was supported by Fundação de Amparo à Pesquisa do Estado de São Paulo (FAPESP) (no. 07/56682-1)

\section{References}

Akahira, Y., Sakagami, S. F. and Zucchi, R. (1970). Die Nähreier von Arbeiterinnen einer stachellosen Biene, Trigona (Scaptotrigona) postica, die von der Königin kurz vor der eigenen Eiablage gefressen werden. Zool. Anz. 185, 85-93.

Amsalem, E., Kiefer, J., Schulz, S. and Hefetz, A. (2014). The effect of caste and reproductive state on the chemistry of the cephalic labial glands secretion of Bombus terrestris. J. Chem. Ecol. 40, 900-912.

Arnold, G. and Delage-Darchen, B. (1978). Nouvelles données sur l'équipement enzymatique des glandes salivaires de l'ourivière d' Apis mellifera (Hyménoptère, Apide). Ann. Sci. Nat. Zool. 20, 401-422.

Arnold, G., Quenet, B., Cornuet, J.-M., Masson, C., de Schepper, B., Estoup, A. and Gasqui, P. (1996). Kin recognition in honey bees. Nature 379, 498.

Bego, L. R. (1982). On social regulation in Nannotrigona (Scaptotrigona) postica Latreille, with special reference to male production cycles (Hymenoptera, Apidae, Meliponinae). Bol. Zool. Univ. São Paulo 7, 181-196.

Bergman, P. and Bergström, G. (1997). Scent marking, scent origin, and species specificity in male premating behavior of two Scandinavian bumblebees. J. Chem. Ecol. 23, 1235-1251.

Bergström, G., Appelgren, M., Svensson, B. G., Ågren, L., Descoins, C., Frerot, B., Gallois, M. and Lettere, M. (1985). Marking pheromones of Megabombus sylvarum (L.) and M. ruderarius (Müller) males (Hymenoptera: Apidae). Apidologie 16, 57-68.

Bertsch, A., Schweer, H., Titze, A. and Tanaka, H. (2005). Male labial gland secretions and mitochondrial DNA markers support species status of Bombus cryptarum and B. magnus (Hymenoptera, Apidae). Insectes Soc. 52, 45-54. 
Coppée, A., Terzo, M., Valterová, I. and Rasmont, P. (2008). Intraspecific variation of the cephalic labial gland secretions in Bombus terrestris (L.) (Hymenoptera: Apidae). Chem. Biodivers. 5, 2654-2661.

Cruz-Landim, C. (1967). Estudo comparativo de algumas glândulas das abelhas (Hymenoptera, Apoidea). Arq. Zool. 15, 177-290.

Dias, L. B. L. and Simões, D. (1972). Relação entre estrutura etária (normal e anormal) de colônias de Scaptotrigona postica Latreille e desenvolvimento glandular. In Homenagem à Warwick E. Kerr, (ed. C. Cruz-Landim, N. I. Hebling, E. Lello and C. S. Takahashi), pp. 135-142. Rio Claro: Faculdade de Filosofia Ciências e Letras.

Elias-Santos, D., Fialho, M. d. C. Q., Vitorino, R., Oliveira, L. L., Zanuncio, J. C. and Serrão, J. E. (2013). Proteome of the head and thorax salivary glands in the stingless bee Melipona quadrifasciata anthidioides. Apidologie 44, 684-698.

Francke, W., Schröder, W., Engels, W. and Engels, E. (1983). Variation in cephalic volatile substances in relation to worker age and behaviour in the stingless bee, Scaptotrigona postica. Z. Naturforsch. 38c, 1066-1068.

Heselhaus, F. (1922). Die Hautchüsen der Apiden und Verwandter formen. Zool. Jahrb. Abt. Anat. Ontog. Tiere. 43, 363-464.

Jarau, S., Hrncir, M., Zucchi, R. and Barth, F. G. (2004). A stingless bee uses labial gland secretions for scent trail communication (Trigona recursa, Smith 1863). Comp. Physiol. A Neuroethol. Sens. Neural. Behav. Physiol. 190, 233-239.

Jarau, S., Schulz, C. M., Hrncir, M., Francke, W., Zucchi, R., Barth, F. G. and Ayasse, M. (2006). Hexyl decanoate, the first trail pheromone compound identified in a stingless bee, Trigona recursa. J. Chem. Ecol. 32, 1555-1564.

Jarau, S., Dambacher, J., Twele, R., Aguilar, I., Francke, W. and Ayasse, M. (2010a). The trail pheromone of a stingless bee, Trigona corvina (Hymenoptera, Apidae, Meliponini), varies between population. Chem. Sens. 35, 593-601.

Jarau, S., van Veen, J. W., Twele, R., Reichle, C., Gonzales, E. H., Aguilar, I., Francke, W. and Ayasse, M. (2010b). Workers make the queens in melipona bees: identification of geraniol as a caste determining compound from labial glands of nurse bees. J. Chem. Ecol. 36, 565-569.

Johnson, B. R. (2010). Division of labor in honeybees: form, function, and proximate mechanisms. Behav. Ecol. Sociobiol. 64, 305-316.

Kovats, E. (1958). Gas-chromatographische Charakterisierung organischer Verbindungen. Teil 1: retentionsindices aliphatischer Halogenide, Alkohole, Aldehyde und Ketone. Helv. Chim. Acta 41, 1915-1932.

Kullemberg, B., Bergström, G., Bringer, B., Calberg, B. and Cederberger, B. (1973). Observation of scent marking by Bombus Latr. and Psithyrus Lep. Males (Hym., Apidae) and localization of site of production of the secretion. Zoom. Suppl. 1, 23-30.

Michener, C. D. (2007). The Bees of the World. Baltimore: Johns Hopkins University Press.

Morgan, E. D. (1990). Preparation of small-scale samples from insect for chromatography. Anal. Chim. Acta 236, 227-235.
Oster, G. F. and Wilson, E. O. (1978). Caste and Ecology in Social Insects. Princeton: Princeton University Press.

Paxton, R. J. (2000). Genetic structure of colonies and a male aggregation in the stingless bee Scaptotrigona postica, as revealed by microsatellite analysis. Insectes Soc. 47, 63-69.

Poiani, S. B. (2012). A glândula salivar cefálica e os compostos da secreção e de superfície cuticular em algumas espécies de abelhas eussociais (Hymenoptera, Apinae). PhD Thesis, University of São Paulo State.

Poiani, S. B. and Cruz-Landim, C. (2009). Cephalic salivary gland ultrastructure of worker and queen eusocial bees (Hymenoptera, Apidae). Anim. Biol. 59, 299-311.

Poiani, S. B. and Cruz-Landim, C. (2010a). Morphological changes in the cephalic salivary glands of females and males of Apis mellifera and Scaptotrigona postica (Hymenoptera, Apidae). J. Biosc. 35, 249-255.

Poiani, S. B. and Cruz-Landim, C. (2010b). Changes in the size of cephalic salivary glands of Apis mellifera and Scaptotrigona postica (Hymenoptera: Apidae) queens and workers in different life phases. Zoologia 27, 961-964.

Poiani, S. B. and Cruz-Landim, C. (2010c). Cephalic salivary glands of two species of advanced eusocial bees (Hymenoptera: Apidae): morphology and secretion. Zoologia 27, 979-985.

Ribbands, R. (1953). The Behaviour and Social Life of Honeybees. New York: London Dover Publ Inc.

Santos, C. G. D., Megiolaro, F. L., Serrão, J. E. and Blochtein, B. (2009). Morphology of the head salivary and intramandibular glands of the stingless bee Plebeia emerina (Frise) (Hymenoptera, Meliponini) workers associated with propolis. Ann. Entomol. Soc. Am. 102, 137-143.

Schorkopf, D. L. P., Jarau, S., Francke, W., Twele, R., Zucchi, R., Hrncir, M., Schmidt, V. M., Ayasse, M. and Barth, F. G. (2007). Spitting out information: Trigona bees deposit saliva to signal resource locations. Proc. R. Soc. B Biol. Sci. 274, 895-899.

Simpson, J. (1960). The functions of the salivary glands of Apis mellifera. J. Insect Physiol. 4, 107-121.

Singer, T. L. and Espelie, K. E. (1992). Social wasps use nest paper hydrocarbons for nestmate recognition. Anim. Behav. 44, 63-68.

Šobotník, J., Kalinová, B., Cahlíková, L., Weyda, F., Ptáček, V. and Valterová, I. (2008). Age-dependent changes in structure and function of the male labial gland in Bombus terrestris. J. Insect Physiol. 54, 204-214.

Stangler, E. S., Jarau, S., Hrncir, M., Zucchi, R. and Ayasse, M. (2009). Identification of trail pheromone compounds from the labial glands of the stingless bee Geotrigona mombuca. Chemoecol 19, 13-19.

Terzo, M., Valterová, I. and Rasmont, P. (2007). Atypical secretions of the male cephalic labial glands in bumblebees: the case of Bombus (Rhodobombus) mesomelas Gerstaecker (Hymenoptera, Apidae). Chem. Biodiversity 4, 1466-1471. 